\title{
Management of acute Achilles Tendon Ruptures: Challenges and Future
}

\author{
Yahong $\mathrm{Wu}^{1}$, Yuan $\mathrm{Mu}^{1}$, Zhuoqun Wang ${ }^{1}$, Lifeng $\mathrm{Guo}^{1}$ and Liangjun Yin ${ }^{1 *}$ \\ Department of Orthopedics, Chongqing Medical University, China

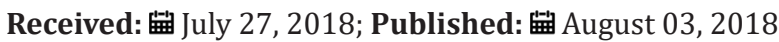 \\ *Corresponding author: Liangjun Yin, Department of Orthopedics, Second Affiliated Hospital of Chongqing, Medical University, \\ Chongqing 400010, China
}

\begin{abstract}
The incidence of Achilles tendon rupture (ATR) has continue to increase in the last decade. A successful management of ATR is based on both the treatment intervention as well as rehabilitation regimens. Treatments for the Achilles tendon ruptures can be divided into conventional treatment, minimally invasive surgery and open surgery. The rehabilitation protocols are highly diverse but can be classified as early immobilization and accelerated rehabilitation. The relative benefits of all managements remain a subject of debate due to the constantly changing effectiveness standard for ATR repair. Complications incidence is a universal measure that could be explored to comparing different managements. The reported incidence of major complications is controversial and different managements demonstrate a disparate complication spectrum. In the future, efforts should be made in exploring more the optimal treatment and rehabilitation protocol. The ideal surgical intervention would be both minimally invasive to reduce complications and strong enough to withstand accelerated rehabilitation.
\end{abstract}

\section{Mini Review}

Achilles tendon is the thickest and strongest tendon in human body. It is also the tendon that most vulnerable to rupture. The incidence of Achilles tendon rupture (ATR) has continue to increase in the last decade [1]. In Denmark, the annual incidence was 55.2 and 14.7 (all member per 10,000) for the males and the females respectively in 2012 , with a $22 \%$ rise comparing to 2001 [2]. A palpable gape and positive Thompson test as well as Ultrasonography and magnetic resonance image is applied to the diagnosis of ATR. A successful management of ATR is based on both the treatment intervention as well as rehabilitation regimens. Treatments for the Achilles tendon ruptures can be divided into conventional treatment, minimally invasive surgery and open surgery [3-5]. The rehabilitation protocols are highly diverse but can be classified as early immobilization and accelerated rehabilitation [6-11].

Unlike the former one that features on long time of immobilization of injured ankle, the accelerated rehabilitation is aim to achieve an enhanced tendon healing and eventually a shorted return to work time for patients by using a variety of methods like early mobilization, early weight bearing etc. The relative benefits of all managements remain a subject of debate. One of the reasons for failure to reach a consensus is because the effectiveness standard for ATR repair is constantly changing. In the early day functional measures such as Rang of Motion (ROM) were in the center of interest. Later on, several comprehensive score systems that concern not only objective measures but also patients' subjective satisfaction have introduced and widely accepted $[12,13]$. In recent days, measures that focused on patient's life quality have been given more and more attention, such as return to work time and activity restoration [8].

This shit in effectiveness standard represents the changing idea for the optimal management of ATR repair. It also prevents the overall comparisons between different managements. But there is a universal measure that could be explored to comparing different managements----complications. Complications after ATR could be minor like skin related complications (adhesion, superficial infection, etc.), tendon related complications (elongation, contracture), pain and sural nerve disturbance. Though these minor complications would prolong the healing process, the negative effect is reversible. But major complications such as re-rupture, deep infection and DVT would result in a surgical intervention, prolonged hospital time or even life threating leading to a total failure of management. The gravity of major complications makes them paramount in treatment as well as recovery. The reported incidence of major complications is controversial and different managements demonstrate a disparate complication spectrum [8,14-17].

Conservative treatment is often associated with a higher rerupture rate. Deng discovered that re-rupture occurred in $3.7 \%$ surgically treated patients and $9.8 \%$ nonsurgical treated patients with statistical significance [18]. In another meta-analysis, Amendola found that the pooled rate of tendon reruptures was 
lower in those treated surgically, 3.6\%, compared with $8.8 \%$ for patients managed nonoperatively [19]. Wilkins has pointed out that Open repair was associated with a significantly lower rerupture rate compared with nonoperative treatment (3.6\% vs $8.8 \%$ ) [20]. As for open surgery and minimally invasive surgery, more and more studies have pointed out that MIS is better than open surgery. It would not only reduce complication incidence [3], but also show superiority in clinical outcomes than open surgery [21]. However, due to its limited incision and poor exposure, MIS is reported to associate with sural nerve injury, especially in percutaneous repair. In a study of 31ATR patients who underwent percutaneous repair, a total of five sural nerve injuries $(16 \%)$ have been detected. But the symptoms resolved in 6 to 9 months [22].

For rehabilitation regimens, numerous studies have demonstrated that accelerated rehabilitation promotes early healing and contributes to functional recovery [23-25]. It would also lead to a shorted return to sports time and a higher patient satisfaction [26]. Accelerated rehabilitation also facilitates tendon repair by allowing ankle to move. Studies have also shown that mesenchymal stem cells play a key role in tendon healing and physical stimulation has a major impact on them [27-30]. More important, providing patients with an enhanced recovery and shorted return to normal life time is becoming a common goal for all sports medicine doctors.

In the future, efforts should be made in exploring more the optimal treatment and rehabilitation protocol. The detailed standardization rehabilitation protocols should be established instead of present diverse regimens. The key is about early motion of the injury ankle to facilitate tendon healing. Therefore, the ideal surgical intervention would be both minimally invasive to reduce complications and strong enough to withstand accelerated rehabilitation. The emerging novel MIS called Panda Rope Bridge Technique is one example. Further researches on the function of different arguments, sutures and mechanism of Achilles tendon repair are also needed [27,31-33].

\section{Funding}

This article was supported by research grants from the Chongqing science and Technology Commission social and people's livelihood project (cstc2018jscx-msybX0088).

\section{References}

1. Uquillas CA, Guss MS, Ryan DJ, Jazrawi LM, Strauss EJ (2015) Everything Achilles: Knowledge Update and Current Concepts in Management: AAOS Exhibit Selection. The Journal of bone and joint surgery American volume 97(14): 1187-1195.

2. Ganestam A, Kallemose T, Troelsen A, Barfod KW (2016) Increasing incidence of acute Achilles tendon rupture and a noticeable decline in surgical treatment from 1994 to 2013. A nationwide registry study of 33,160 patients. Knee surgery, sports traumatology, arthroscopy : official journal of the ESSKA 24: 3730-3737.

3. Aktas S, Kocaoglu B (2009) Open versus minimal invasive repair with Achillon device. Foot \& ankle international 30: 391-397.

4. Metz R, Verleisdonk EJ, van der Heijden GJ, Clevers GJ, Hammacher ER, et al. (2008) Acute Achilles tendon rupture: minimally invasive surgery versus nonoperative treatment with immediate full weightbearing--a randomized controlled trial. The American journal of sports medicine
36: $1688-1694$

5. Gigante A, Moschini A, Verdenelli A, Del Torto M, Ulisse S, et al. (2008) Open versus percutaneous repair in the treatment of acute Achilles tendon rupture: a randomized prospective study. Knee surgery, sports traumatology, arthroscopy : official journal of the ESSKA 16: 204-209.

6. Valkering KP, Aufwerber S, Ranuccio F, Lunini E, Edman G, et al. (2017) Functional weight-bearing mobilization after Achilles tendon rupture enhances early healing response: a single-blinded randomized controlled trial. Knee surgery, sports traumatology, arthroscopy : official journal of the ESSKA 25(6): 1807-1816.

7. Lantto I, Heikkinen J, Flinkkila T, Ohtonen P, Kangas J, et al. (2015) Early functional treatment versus cast immobilization in tension after achilles rupture repair: results of a prospective randomized trial with 10 or more years of follow-up. The American journal of sports medicine 43(9): 2302-2209.

8. Young SW, Patel A, Zhu M, van Dijck S, McNair P, et al. (2014) WeightBearing in the Nonoperative Treatment of Acute Achilles Tendon Ruptures: A Randomized Controlled Trial. The Journal of bone and joint surgery American volume 96: 1073-1079.

9. Suchak AA, Bostick GP, Beaupre LA, Durand DC, Jomha NM (2008) The influence of early weight-bearing compared with non-weight-bearing after surgical repair of the Achilles tendon. The Journal of bone and joint surgery American volume 90(9): 1876-1883.

10. Kangas J, Pajala A, Siira P, Hamalainen M, Leppilahti J (2003) Early functional treatment versus early immobilization in tension of the musculotendinous unit after Achilles rupture repair: a prospective, randomized, clinical study. The Journal of trauma 54(6): 1171-1180.

11. Mortensen H, Skov O, Jensen P (1999) Early motion of the ankle after operative treatment of a rupture of the Achilles tendon. A prospective, randomized clinical and radiographic study. Journal of bone and joint surgery American volume 81(7): 983-990.

12. Leppilahti J, Forsman K, Puranen J, Orava S (1998) Outcome and prognostic factors of achilles rupture repair using a new scoring method. Clinical orthopaedics and related research 346: 152-161.

13. Nilsson Helander K, Thomeé R, Grävare Silbernagel K, Thomeé P, Faxén E, Eriksson BI, et al. (2007) The Achilles tendon total rupture score (ATRS) development and validation. The American journal of sports medicine 35(3): 421-426.

14. Willits K, Amendola A, Bryant D, Mohtadi NG, Giffin JR, et al. (2010) Operative versus nonoperative treatment of acute Achilles tendon ruptures: a multicenter randomized trial using accelerated functional rehabilitation. The Journal of bone and joint surgery American volume 92: 2767-2775.

15. Nilsson Helander K, Silbernagel KG, Thomee R, Faxen E, Olsson N, et al. (2010) Acute achilles tendon rupture: a randomized, controlled study comparing surgical and nonsurgical treatments using validated outcome measures. The American journal of sports medicine 38: 2186-2193.

16. Nilsson Helander K, Thurin A, Karlsson J, Eriksson B (2009) High incidence of deep venous thrombosis after Achilles tendon rupture: a prospective study. Knee surgery, sports traumatology, arthroscopy 17(10): 1234-1238.

17. Barfod KW, Bencke J, Lauridsen HB, Ban I, Ebskov L, et al. (2014) Nonoperative dynamic treatment of acute achilles tendon rupture: the influence of early weight-bearing on clinical outcome: a blinded, randomized controlled trial. The Journal of bone and joint surgery American volume 96: 1497-1503.

18. Deng S, Sun Z, Zhang C, Chen G, Li J (2017) Surgical Treatment Versus Conservative Management for Acute Achilles Tendon Rupture: A Systematic Review and Meta-Analysis of Randomized Controlled Trials. The Journal of foot and ankle surgery: official publication of the American College of Foot and Ankle Surgeons 56(6): 1236-1243. 
19. Amendola A (2014) Outcomes of open surgery versus nonoperative management of acute achilles tendon rupture. Clinical journal of sport medicine: official journal of the Canadian Academy of Sport Medicine 24(1): 90-91.

20. Wilkins R, Bisson LJ (2012) Operative versus nonoperative management of acute Achilles tendon ruptures: a quantitative systematic review of randomized controlled trials. The American journal of sports medicine 40(9): 2154-2160.

21. Avina Valencia JA, Guillen Alcala MA (2009) [Repair of acute Achilles tendon rupture. Comparative study of two surgical techniques]. Acta ortopedica Mexicana 23(3): 125-129.

22. Sutherland A, Maffulli N (1999) A modified technique of percutaneous repair of ruptured Achilles tendon. Orthopedics and Traumatology 7(4): 288-295.

23. Kim U, Choi YS, Jang GC, Choi YR (2017) Early rehabilitation after open repair for patients with a rupture of the Achilles tendon 48(7): 17101713.

24. Jielile J, Asilehan B, Wupuer A, Qianman B, Jialihasi A, Tangkejie W, et al. (2016) Early Ankle Mobilization Promotes Healing in a Rabbit Model of Achilles Tendon Rupture. Orthopedics 39(1): e117-e26.

25. Valkering KP, Aufwerber S, Ranuccio F, Lunini E, Edman G, et al. (2017) Functional weight-bearing mobilization after Achilles tendon rupture enhances early healing response: a single-blinded randomized controlled trial. Knee Surgery, Sports Traumatology, Arthroscopy 25: 1807-1816.

\section{ISSN: 2574-1241}

DOI: 10.26717/BJSTR.2018.07.001526

Liangjun Yin Biomed J Sci \& Tech Res

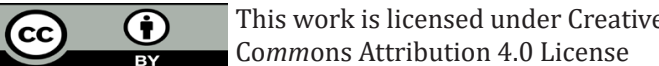

Submission Link: https://biomedres.us/submit-manuscript.php
26. Bhattacharyya M, Gerber B (2009) Mini-invasive surgical repair of the Achilles tendon-does it reduce post-operative morbidity? International orthopaedics 33(1): 151-156.

27. Frith JE, Kusuma GD, Carthew J, Li F, Cloonan N, Gomez GA, et al. (2018) Mechanically-sensitive miRNAs bias human mesenchymal stem cell fate via mTOR signalling. Nature communications 9: 257.

28. Aktas E, Chamberlain CS, Saether EE, Duenwald Kuehl SE, Kondratko Mittnacht J, et al. (2017) Immune modulation with primed mesenchymal stem cells delivered via biodegradable scaffold to repair an Achilles tendon segmental defect. Journal of orthopaedic research : official publication of the Orthopaedic Research Society 35(2): 269-280.

29.Zhang W, Yang Y, Zhang K, Li Y, Fang G (2015) Weft-knitted silkpoly(lactide-co-glycolide) mesh scaffold combined with collagen matrix and seeded with mesenchymal stem cells for rabbit Achilles tendon repair. Connect Tissue Res 56(1): 25-34.

30. Huang TF, Yew TL, Chiang ER, Ma HL, Hsu CY, et al. (2013) Mesenchymal stem cells from a hypoxic culture improve and engraft Achilles tendon repair. The American journal of sports medicine 41(5): 1117-1125.

31. Yin L, Wu Y, Ren C, Wang Y, Fu T, et al. (2018) Treatment of acute Achilles tendon rupture with the panda rope bridge technique. Injury $49(3)$ : 726-729.

32. Heikkinen J, Lantto M, Flinkkila T, Ohtonen P, Pajala A, et al. (2016) Augmented compared with nonaugmented surgical repair after total achilles rupture results of a prospective randomized trial with thirteen or more years of follow-up. Journal of bone and joint surgery - american volume 98(2): 85-92.

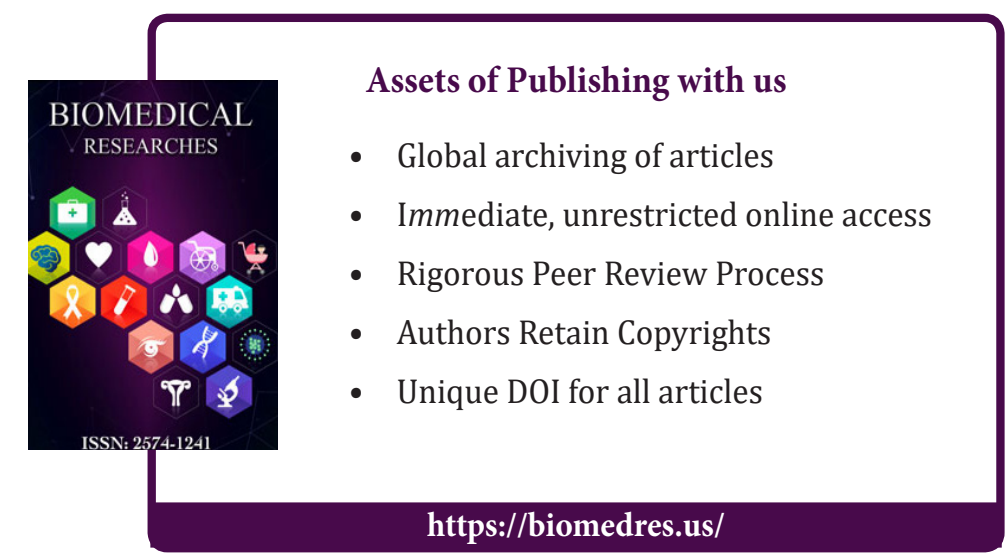

